\title{
LA ESTÉTICA DEL COLLAGE EN LA PROPUESTA DANCÍSTICA DE MERCE CUNNINGHAM
}

\author{
THE COLLAGE AESTHETICS IN \\ MERCE CUNNINGHAM'S APPROACH \\ TO DANCE
}

A ESTÉTICA DA COLAGEM NA PROPOSTA DE DANÇA DE MERCE

CUNNINGHAM
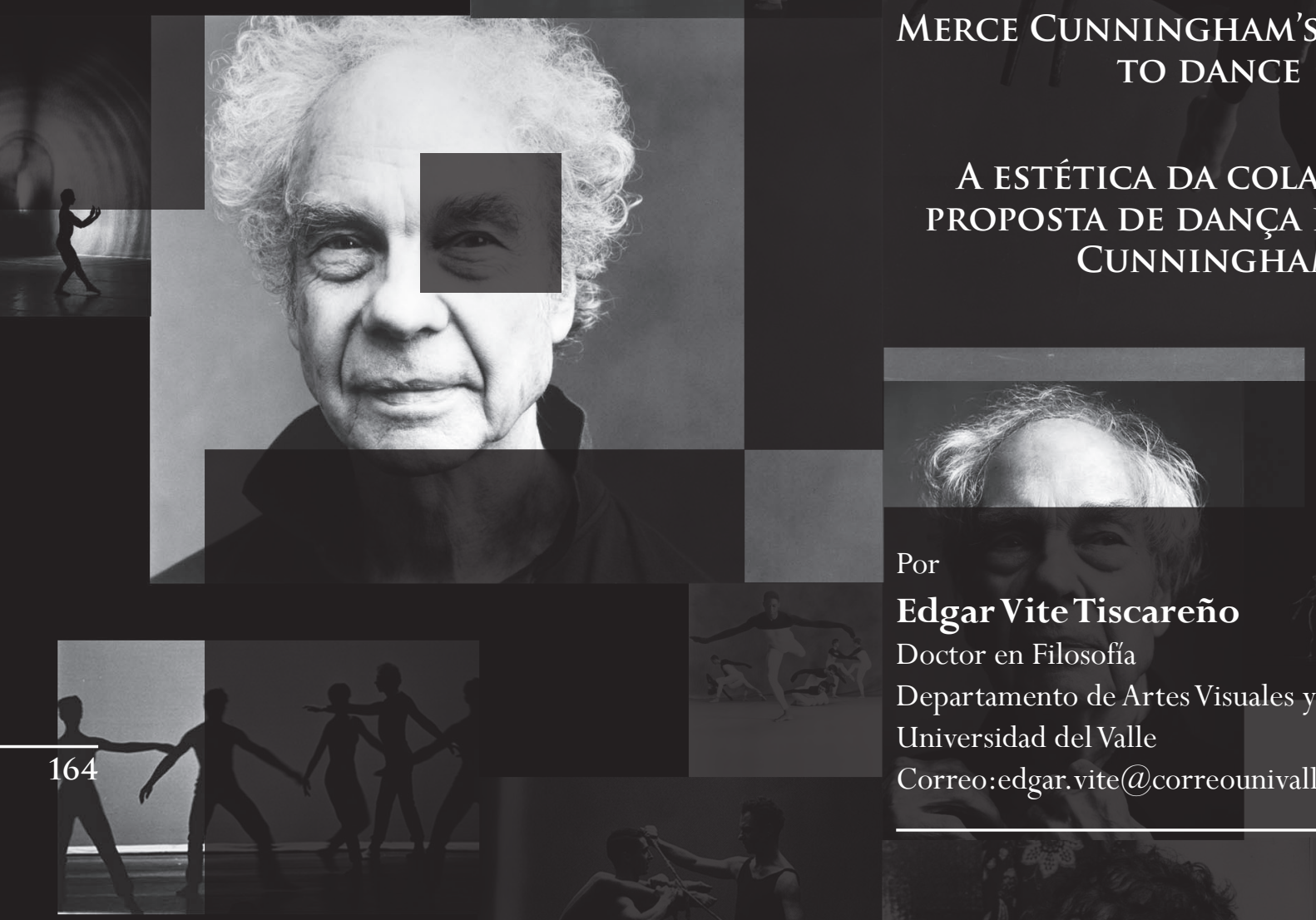

\section{Edgar Vite Tiscareño}

Doctor en Filosofía

Departamento de Artes Visuales y Estética Universidad del Valle

Correo:edgar.vite@correounivalle.edu.co

Resumen: En este texto examino el modo en que la estética del collage no se limitó únicamente al contexto de las propuestas plásticas y visuales, e influyó otros ámbitos. Permeó a las artes escénicas y sobre todo influyó notablemente a la danza moderna y contemporánea. Con esta finalidad reviso detenidamente el trabajo coreográfico de Merce Cunningham, centrándome en su colaboración con diversos artistas, a lo largo de su trayectoria, así como su constante experimentación con los efectos plásticos y visuales de la escenografía, el vestuario y la iluminación. Estos elementos del montaje generan diversas connotaciones del cuerpo, como imagen fragmentada en movimiento, a través de una peculiar interpretación del collage, que termina transfigurado en danza.

Palabras Clave: Estética del collage, Ates Visuales, Artes Escénicas, Danza contemporánea, Merce Cunningham. 
Abstract: In this paper I discuss how the aesthetic of collage is not only connected to the plastic and visual arts, but also very close related to the scenic arts and has a significant influence in modern and contemporary dance. With this goal in mind I analyze the choreographic work of Merce Cunningham, specially his collaboration with different kind of artists along his career. In this sense I defend that it is possible to find in Cunningham's work, a constant experimentation with the plastic and visual effects of the scenography, the costume design, and the scenic illumination. Taking these elements as keys to his work, I show the plural lectures that can be suggested by the dancing body as fragmented image in movement and how the collage is adapted and transfigured into dance.

Keywords: Collage Anesthetic's, Visual Arts, Scenic Arts, Contemporary Dance, Merce Cunningham.

Resumo: Neste texto examino a maneira na qual a estética da colagem não limitou-se somente ao contexto das propostas plásticas e visuais e influiu outros meios. Permeou as artes cênicas e sobre tudo influiu notavelmente à dança moderna e contemporânea. Com este objetivo, reviso cuidadosamente o trabalho coreográfico de Merce Cunningham, focando-me na sua colaboração com diferentes artistas, ao longo da sua trajetória, assim como a sua constante experimentação com os efeitos plásticos e visuais da cenografia, o vestuário e a iluminação. Estes elementos da montagem geram diversas conotações do corpo, como imagem fragmentada em movimento, através de uma particular interpretação da colagem, que torna-se configurando em dança.

Palavras-chave: Estética da colagem, artes visuais, artes cênicas, dança contemporânea, Merce Cunningham.

El collage y su complemento tridimensional, el ensamblaje, están íntimamente asociados con las agudas disyunciones y peculiares yuxtaposiciones propias de la experiencia urbana del siglo XX.

Roger Copeland, 2002

\section{Influencias y puntos de encuentro en la obra de Cunningham}

Un aspecto central en el desarrollo de la carrera de Merce Cunningham consiste en que durante los años que enseñó en Black Mountain College, conoció a John Cage, quien ejerció una fuerte influencia en su trabajo coreográfico y con quien trabajó intensamente, hasta los últimos días de su vida. Su relación con Cage se tradujo en una serie de experimentos musicales en sus coreografías, que en la mayoría de los casos implicaban una asincronía entre el tempo musical y los movimientos de los bailarines. Este rasgo nos hace pensar en la multiplicidad de elementos que caracterizaban las coreografías de Cunningman y la complejidad de atmósferas que creaba, lo que desde mi perspectiva constituye una concepción del cuerpo como imagen en movimiento, mediante la cual generaba una amplia gama de experiencias sensoriales. 
Ambos artistas partían de una cierta idea común y sobre todo de una estructura musical y coreográfica que no permanecía estática, iba siendo modificada conforme avanzaban en el proceso de composición. En muchas ocasiones no ensayaban previamente, esperaban hasta el estreno de la pieza en el escenario y daban un margen muy amplio para la improvisación musical y dancística, involucrando elementos que no podían controlar del todo y que permitían un amplio juego de posibilidades. Al respecto, el mismo Cunningham (1982) nos habla del modo particular en que ambos trabajaban:

En un principio las piezas solían ser más cortas y existía una cierta estructura rítmica más definida. John solía hacer preguntas, él deseaba saber cuántos bailarines participarían y cómo sería la estructura.

Después gradualmente fuimos capaces de trabajar de modo que incluso no era necesario hablar entre nosotros. Se convirtió más en un proceso, que en un objeto mezclado. (1982, p. 338)

Un rasgo que es sumamente notable en la propuesta musical de John Cage, que también puede apreciarse en el trabajo coreográfico de Merce Cunningham, es que ninguno de los dos se centró únicamente en su campo específico, sus proyectos se caracterizaron por transitar constantemente entre disciplinas artísticas y por nutrirse de estas interacciones. Kostelanetz enfatiza este aspecto de la trayectoria artística de John Cage: "Para 1990 es muy claro que John Cage no sólo era un compositor, ni propiamente un escritor, sino un verdadero artista múltiple, lo que significa que produjo notables obras en más de una disciplina artística, que no fue adyacente a la música” (1991, p. 323).

En este mismo sentido, Cage tomó en cuenta las propiedades visuales de ciertos elementos musicales en sus obras, como fue el hecho de resaltar la dimensión gráfica y estética de la notación musical, en algunos de sus proyectos artísticos. De este modo, encontramos un trabajo que realizó como homenaje a Marcel Duchamp, consistió en la creación de un tablero de ajedrez, tomando en cuenta la obsesión de dicho artista francés por este juego de estrategia. El tablero diseñado por Cage contenía un pentagrama con notas musicales en blanco y negro, que contrastaban con el color de la cuadrícula del tablero, lo que daba el efecto de eliminar la continuidad notacional de la partitura escrita y por lo tanto permitía la lectura de la misma en cualquier dirección. (Kostelanetz, 1991, p. 323-324)

Además, durante su época en Black Mountain College, Cunningham tuvo oportunidad de enseñar y conocer a dos jóvenes pintores estadounidenses, quienes después conformaron la famosa Beat Generation. Me refiero concretamente a Jasper Johns y a Robert Rauschenberg. Colaboraron con él en varias ocasiones, en el diseño del vestuario y la escenografía de sus coreografías. En el terreno pictórico, cabe destacar que la Beat Generation se caracterizó por ser el puente de transición entre el Expresionismo Abstracto y el Pop Art, de hecho los artistas de esta generación llevaron a cabo una vuelta a la figuración pictórica, conservando algunos principios estéticos y formales del arte abstracto, pero alejándose de su marcado psicologismo, así como de cualquier lectura emocional adjudicada a sus obras. 
Desde mi perspectiva, lo más relevante de la colaboración entre Merce Cunningham y los artistas de otras disciplinas, consiste en el papel predominante que tuvo la experimentación plástica y visual en sus coreografías y sus puestas en escena, lo que será un rasgo central de lo que puede entenderse como una estética del collage aplicada a la danza. Más adelante ahondaré en las particularidades de la conexión entre los miembros de la Beat Generation y Merce Cunningham, por ahora baste mencionar que existió un mutuo entendimiento entre ellos y un fuerte interés por experimentar con la hibridación, lo que los influyó entre sí y los llevó a colaborar en múltiples ocasiones: "Desde el principio existió entre ellos un sentido de absoluta identificación o mutuo acuerdo. En Black Mountain ellos pudieron apreciar todas las pinturas blancas de Rauschenberg por primera vez, lo que influyó a Cage y lo llevó a escribir su famosa pieza silente 4'33"' (Vaughan, 1983, p. 332)

\section{Rasgos de su técnica y de su proceso creativo}

Al inicio de su carrera, Cunningham tuvo la oportunidad de estudiar directamente con Martha Graham en Nueva York e incluso de pertenecer a su compañía; esto nos habla del legado dancístico de este bailarín y coreógrafo, así como su importancia en el desarrollo de la danza contemporánea. En este mismo sentido, es necesario resaltar que a pesar de la influencia que ejerció en él la técnica y el método de Graham, Cunningham se dedicó a experimentar con otras concepciones de la danza y del movimiento, tomando en cuenta la relación del bailarín con el espacio, la estructura y configuración del trabajo coreográfico, así como el montaje y la puesta en escena.

El estilo particular de Cunningham, en contraste con la propuesta dancística de Martha Graham, consistió en el marcado interés del primero por la dimensión plástica y escultórica del cuerpo humano. Esto se debe a que Cunningham se enfocó en los rasgos formales y estéticos de los bailarines en sus coreografías, distanciándose de la dimensión dramática y psicológica, que predominó en la propuesta de Graham. Sobre este aspecto, del trabajo de Cunningham es necesario resaltar la influencia que tuvo por parte de los montajes escénicos de George Balanchine, quien exploró notablemente el papel del movimiento en la danza, pero sobre todo la dimensión espacial de los cuerpos y sus connotaciones escultóricas. (Vaughan, 1983, p. 330.)

Un aspecto central de la propuesta de Cunningham, que se vincula con los valores e intereses que predominaron en el arte postvanguardista, se refiere al modo en que incluía el azar en sus procesos creativos, lo que no es un rasgo exclusivo de sus coreografías, sino que predominó en el arte de aquella época, debido a la influencia de las técnicas empleadas por los surrealistas 
y los dadaístas. Al respecto, cabe destacar el surgimiento de los happenings, que deben su origen a la aparición del performance, durante las vanguardias artísticas, así como la inclusión de la casualidad y la improvisación en los procesos creativos. Sobre este punto, David Vaughan (1983) plantea el modo minucioso en que Cunningham empleaba el azar, como proceso central en el desarrollo de sus coreografías:

Cunningham usó mecanismos que involucraban el azar para determinar el orden en que aparecerían sus bailes, pero también en el modo en que se conformaría la coreografía en escena; él le asignaba un cierto número de movimientos a cada bailarín y después determinaba la secuencia de los movimientos, la duración y la dirección lanzando monedas. (1983, p. 331)

Como lo he mencionado previamente, un aspecto clave en su proceso de composición fue la fragmentación de elementos, lo que terminó dando paso a una técnica creativa autónoma, que le permitió tanto a John Cage, como a Merce Cunningham trabajar de manera independiente y después ensamblar la pieza en escena durante el estreno, sin la necesidad de ensayar con antelación: "Escoger este tipo de estructura, le permitía a él y a su compositor, John Cage, trabajar de modo independiente en la música y en el movimiento. Este fue el primer ejemplo en danza que mostraba cómo juntar elementos, que no tenían nada que ver entre sí” (Johnston, 1965, p. 334.)

Todos los elementos que he planteado sobre la técnica y el proceso creativo de Merce Cunningham nos muestran claramente que para él no era relevante la integración de toda la puesta en escena y de hecho en la mayoría de sus trabajos disociaba la música del baile, haciendo manifiesto que la danza no tiene porqué subordinarse a la composición musical, sino que ambas disciplinas artísticas pueden conectarse en un mismo tiempo y lugar, sin que implique necesariamente una fusión entre ellas.

En este sentido, la clave para comprender el collage dancístico en el trabajo de Cunningham implica tomar en cuenta la conjunción de estímulos y percepciones sensibles, que no se integran homogéneamente en su propuesta coreográfica, ni en sus montajes, funcionan como fragmentos; es decir, como piezas independientes, que convergen en un mismo espacio y tiempo, lo que genera una nueva gama de experiencias en el espectador, así como en la interpretación coreográfica por parte de los bailarines.

\section{La estética del collage en Merce Cunningham}

En este apartado discutiré detenidamente lo que he denominado como la estética del collage en el campo dancístico y cómo se desarrolló este tipo de hibridación en el trabajo coreográfico de Merce Cunningham. Sobre este punto, cabe destacar su interés por artistas europeos como Max Ernst eYves Tanguy, por artistas 
estadounidenses como Willen de Kooning y Jackson Pollock, así como por la literatura experimental que se desarrolló durante su época, destacando la compleja y enigmática obra de James Joyce. Esto nos muestra de dónde surgió la idea de fragmentación que obsesionó a Cunningham, a lo largo de su carrera (Vaughan, 1983, p. 329).

El collage dancístico en la obra de Cunningham se basa inicialmente en su idea de que la música debía ser independiente a los movimientos de los bailarines, es decir, no tenía que producirse una sincronía, ni una continuidad de los pasos, ni de las secuencias coreográficas, con respecto a la composición musical. Esto nos muestra una superposición de elementos que rompe con los paradigmas de la danza clásica y concretamente del ballet, a su vez nos revela porqué Cunningham rechazó la dimensión emocional, que suele articularse al despliegue narrativo de buena parte de los proyectos coreográficos. La mayoría de los músicos que trabajaban con Cunningham componían una pieza, teniendo sólo como referente la duración de la misma, de modo que los bailarines ensayaban sus movimientos en silencio y escuchaban la música hasta el día del estreno (Vaughan, 1983, p. 331).

De aquí surge el distanciamiento de los principios coreográficos que dominaban el método y la técnica desarrollados por Martha Graham en la danza moderna, pues Cunningham deseaba eliminar toda carga subjetiva y toda posible lectura emocional en sus montajes. Por ello, rechazaba tajantemente una interpretación psicológica de sus piezas, generando distanciamiento frente a movimientos pictóricos como el Expresionismo Abstracto, para el que resultaba fundamental este tipo de aproximación: "Para él, el significado o interpretación de una obra depende del contexto perceptual. Las coreografías de Cunningham no se inclinan por una interpretación psicológica, lo que tampoco quiere decir que su propuesta carezca de una textura emocional" (Copeland, 2002, p. 18).

David Vaughan sostiene que esta neutralización era común al trabajo de John Cage y Merce Cunningham, así como en la mayoría de los representantes de la Beat Generation. Esto es particularmente notable en el trabajo pictórico y plástico de los artistas que pertenecieron a dicha generación, quienes enfatizaban las propiedades formales de sus obras: "Esto era lo que buscaba eliminar Cunningham de sus coreografías y Cage de su música. Tal como lo hizo Marcel Duchamp, ellos deseaban realizar trabajos que no fueran producto de sus emociones personales. Rauschenberg y Jasper Johns también tomaron una actitud semejante" (Vaughan, 1983, p. 332.).

Un ejemplo de este tipo de neutralización podemos encontrarlo en el trabajo pictórico de Jasper Johns, quien se caracterizó por distanciarse del arte abstracto y volver a lo figurativo, pintando objetos de la vida cotidiana, que resultaran indiferentes al espectador 
y llevando a cabo una constante reflexión sobre el papel de la representación en el arte. En esta misma línea, es indispensable hablar de la propuesta plástica de Robert Rauschenberg, quien adhería a sus piezas objetos que encontraba en la calle y se llevaba a su estudio para trabajar con ellos. Mediante estos fragmentos de realidad, Rauschenberg creó sus famosos combinados, que constituyen un tipo muy particular de ensamblaje, mediante el cual este pintor estadounidense llevó al extremo la yuxtaposición que puede encontrarse en el collage pictórico. Esto nos permite ver la fuerte influencia de la concepción plástica de la Beat Generation en la concepción dancística de Merce Cunningham, tanto en lo referente a la fragmentación, como a la neutralización emocional en el arte.

De modo análogo al collage pictórico, el collage dancístico se caracteriza porque presenta una simultaneidad de elementos, pero en este último caso incluye la realización de una secuencia de movimientos en un mismo espacio y la presentación de múltiples perspectivas del cuerpo, lo que nos hace pensar en las obras pictóricas de los futuristas y los cubistas. En las coreografías de Cunningham, esta simultaneidad de elementos se asocia también con la autonomía entre música y danza, lo que implica un contraste interesante entre los movimientos y los sonidos experimentados, así como entre las imágenes corporales y las estructuras musicales. Esto dio lugar a un nuevo lenguaje dancístico: "No existe una mejor descripción de trabajo de Cunningham, que campo abierto, caracterizado por su lenguaje de movimiento fragmentado, sus múltiples entradas y salidas, así como su resonante y reversible conexión entre imagen, sonido y escenografía" (Copeland, 2002, p. 26).

Cunningham puso un fuerte acento en los efectos visuales de sus coreografías y a su vez se interesó por experimentar con los nuevos medios audiovisuales, como ocurrió con la aparición del video. En esta línea, trabajó con diversos realizadores, poniendo especial atención en los efectos que pueden originarse, a partir de la simultaneidad de imágenes y los planos espaciales de un montaje fílmico, de forma análoga a la yuxtaposición que realizaba en la composición de sus puestas en escena. La experimentación de Cunningham con el video puede apreciarse en Torso de 1978, que involucró la proyección de dos filmes, con una duración de 55 minutos cada uno, situados adyacentemente, con la intención de mostrar que no existe una mirada unívoca del público hacia la imagen, sino que en una misma obra pueden converger perspectivas asimétricas (Copeland, 2002, p. 22).

Cunningham era muy consciente de la dimensión plástica de los cuerpos de los bailarines en el escenario y este fue un rasgo que exploró desde diversos ángulos. Por ello, en sus proyectos coreográficos no sólo tomaba en cuenta los efectos visuales de la escenografía, del vestuario y de los juegos de luces, sino que trabajó con la dimensión escultórica, que puede hallarse en los cuerpos en movimiento y su interacción con el espacio del escenario. Un ejemplo de esto, puede apreciarse en una obra llamada Cuadros de 1984, donde los bailarines se enlazan entre sí, en una compleja estructura de cuerpos múltiples, con fuertes connotaciones escultóricas y plásticas (Copeland, 2002, p. 25). 
Otro elemento que cabe resaltar sobre la conexión del trabajo coreográfico de Merce Cunningham con la estética del collage y su traducción al terreno de la danza, se debe a que en una misma propuesta, él empleaba una amplia gama de ritmos musicales y de diferentes tipos de baile, pero sobre todo involucraba una gran variedad de gestos, actitudes y movimientos, que no se consideran propiamente dancísticos, sino que más bien pueden hallarse en contextos cotidianos, en ritmos de la vida diaria y en espacios lejanos al ámbito artístico. La inclusión de estos elementos es central en los procesos creativos de la danza contemporánea, pero en el caso de Cunningham nos permite ver cómo entendía la yuxtaposición desde el movimiento corporal y desde una gran diversidad de concepciones sobre la danza (Vaughan, 1983, p. 332).

De este modo, encontramos una serie de categorías muy particulares en el trabajo coreográfico y dancístico de Cunningham, que nos muestran una interesante versión en movimiento del collage visual y plástico. En este caso, la fragmentación y reconstrucción de las piezas no se limitan a la superficie plana del lienzo, ni a la superficie tridimensional del espacio escultórico, que suelen ser estáticos y estar confinados a su materialidad. En la propuesta coreográfica de Cunnigham hallamos una constante experimentación con la disociación de elementos, correspondientes a otras disciplinas. Roger Copland sintetiza puntualmente la concepción dancística de Cunnigham y su vínculo con la estética del collage en las siguientes ideas:

El modo en que involucraba el azar para articular fragmentos de movimiento dispares, el modo descentralizado en que situaba a los bailarines a lo largo del escenario durante la presentación e incluso la elección del espectador sobre dónde y cuándo enfocar su atención visual y auditiva (2002, p. 13)

Sobre este mismo aspecto, podemos percatarnos de que el collage dancístico de Cunningham se caracteriza porque no es posible hallar una jerarquización de elementos, ni encontrar un clímax dramático, lo que sugiere que realmente no existe un principio, ni un término del movimiento, ni tampoco un hilo narrativo en la coreografía. Por ello, cuando el espectador observa este tipo de trabajo, cada bailarín se mueve a su propio ritmo y el cuadro completo se asemeja a un espacio de tránsito, donde cada individuo se dirige de modo independiente a su propio destino. $\mathrm{Al}$ respecto, Jill Johnston realiza una interesante analogía con el trabajo pictórico de Jackson Pollock, en lo que concierne a su concepción del espacio más allá del lienzo, lo que de alguna forma puede hallarse en las coreografías de Cunningham:

Se ha enfatizado que las pinturas de Pollock sugieren una extensión infinita, más allá del plano pictórico. Las coreografías de Cunningham sugieren la misma extensión, y como juega constantemente con el orden de las partes al incluir el azar es claro que considera que un comienzo es tan bueno como otro. (Johnston, 1965, 334) 
Para cerrar este apartado deseo enfatizar que Merce Cunningham se mantuvo siempre a la vanguardia, experimentando todo el tiempo con los nuevos avances tecnológicos y hallando formas de involucrarlos en el desarrollo de ideas para sus coreografías, pero sobre todo reflexionando constantemente en su proceso creativo, no desde una perspectiva teórica, sino más bien desde su práctica dancística. De modo que como bailarín y coreógrafo, no sólo empleaba el cuerpo y los movimientos que pueden generarse mediante él, sino que usaba creativamente los materiales, las texturas, los colores y los efectos plásticos y visuales que producen el vestuario, la escenografía, el espacio del escenario y la intervención de las luces en el mismo.

\section{La dimensión plástica y visual en su propuesta coreográfica}

En este espacio examinaré tres coreografías y escenografías de este gran bailarín, que he seleccionado debido a que poseen una fuerte carga visual y desarrollan una interesante poética del collage en su versión dancística, además de que incluyen elementos de diversas disciplinas artísticas en la puesta en escena. En este mismo sentido, retomaré algunos de los aspectos técnicos y sobre todo de las categorías que he planteado hasta ahora, poniendo especial atención en la dimensión visual y plástica de la danza, a través del trabajo colaborativo que llevó a cabo Merce Cunningham para el diseño de las escenografías, del vestuario y de la iluminación característicos de sus montajes.

La primera coreografía a la que me referiré es Camino al estanque de 1998 (Fig. 1), es una pieza que se inspira en lo acuático y sobre todo en los reflejos del agua, así como los efectos visuales y la multiplicidad de sensaciones que genera en el espectador. Esto no significa, que Merce Cunningham emplee literalmente agua en el escenario, como sí lo hizo Pina Bausch en una de sus coreografías más arriesgadas, sino más bien que Cunningham hace uso de una imagen simbólica del agua en la escenografía, que está presente durante toda la ejecución de la danza. Para ello, Cunningham le solicitó a Roy Lichstenstein que realizara la representación de un lago, inspirada en la estética del cómic, que es el sello particular de la obra pictórica de este artista, perteneciente al Pop Art, quien se concibiera a sí mismo como una especie de impresionista postmoderno.

$\mathrm{Al}$ respecto, es relevante señalar que la técnica de Roy Lichstenstein (Fig. 2) recuerda al puntillismo de Georges Seurat, en el que posiblemente se inspiró para desarrollar su propio estilo. Este nuevo tipo de puntillismo surgió de los llamados Ben Day Dots, que se originan por el modo en que se inyecta el color en los cómics, debido a la baja calidad del papel en que solían imprimirse las historietas. Lichtenstein retomó este efecto visual de los cómics y explotó sus propiedades plásticas, destacando la aplicación del color en pequeños círculos que construyen la imagen total, tal como puede apreciarse en la escenografía creada para Camino al estanque.

$\mathrm{h}$ 




Fig.1. Walker Art Center. (2011). Merce Cunningham Dance Company:The Legacy Tour. Minneapolis, Estados Unidos. Recuperada de http:/ /blogs. walkerart.org/performingarts/2011/11/05/ penelope-free-reviews-merce-cunningham-dance-company-the-legacy-tour/

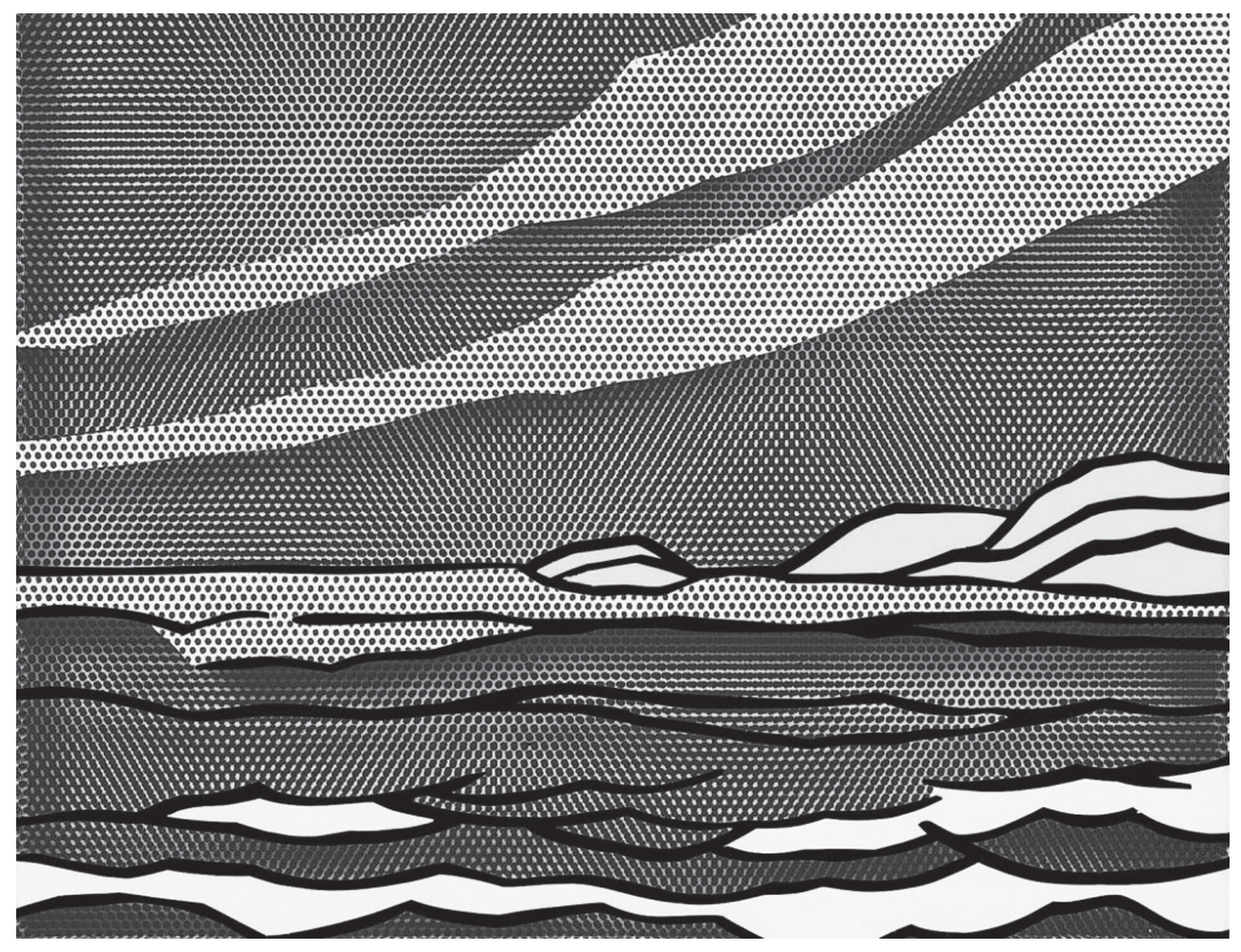

Fig. 2. The Art Institute of Chicago. (2013). Roy Lichtenstein. A Retrospective. Chicago, Estados Unidos. Recuperada de http:/ / www.artic.edu/aic/collections/exhibitions/Lichtenstein/artwork/213407 
Otro rasgo interesante de Camino al estanque consiste en el diseño del vestuario para esta coreografía y el modo en que dialoga con la escenografía. Sobre este punto cabe destacar que el vestuario posee unas aberturas a los costados, lo que no sólo muestra la maleabilidad de la tela, que cae de las extremidades, sino que enfatiza la fluidez de los movimientos, remitiéndonos al desplazamiento del agua y contrastando con la imagen estática del lago, en el fondo del escenario. Además los trajes de los bailarines son blancos, lo que en un principio parecería muy neutral y no genera una gama de color en el montaje, sin embargo tanto la escenografía, como el vestuario son pintados por los juegos de luces. Esto a su vez nos lleva a pensar en la neutralidad emocional que buscaba Cunningham mediante su trabajo, poniendo más atención en los efectos perceptuales y los elementos formales de sus propuestas, que en los rasgos psicológicos y emotivos a los que pudieran dar lugar.

La siguiente coreografía que he seleccionado es Selva, creada en el año de 1968 (Fig. 3), en la que colaboró directamente Andy Warhol, quien al igual que Lichtenstein perteneció al movimiento artístico del Pop Art. La obra pictórica de Warhol se caracterizó por apropiarse de los íconos más representativos de la farándula y de las marcas que consumía la clase media estadounidense, durante la década de los años 60. En este caso, la colaboración entre Cunningham y Warhol llevó a la inclusión de un elemento, que desde mi perspectiva genera una fuerte interacción con el bailarín en el desarrollo de la coreografía, pero también da lugar a una variedad de matices visuales, que resultan atractivos en escena y que producen efectos muy llamativos para el espectador.

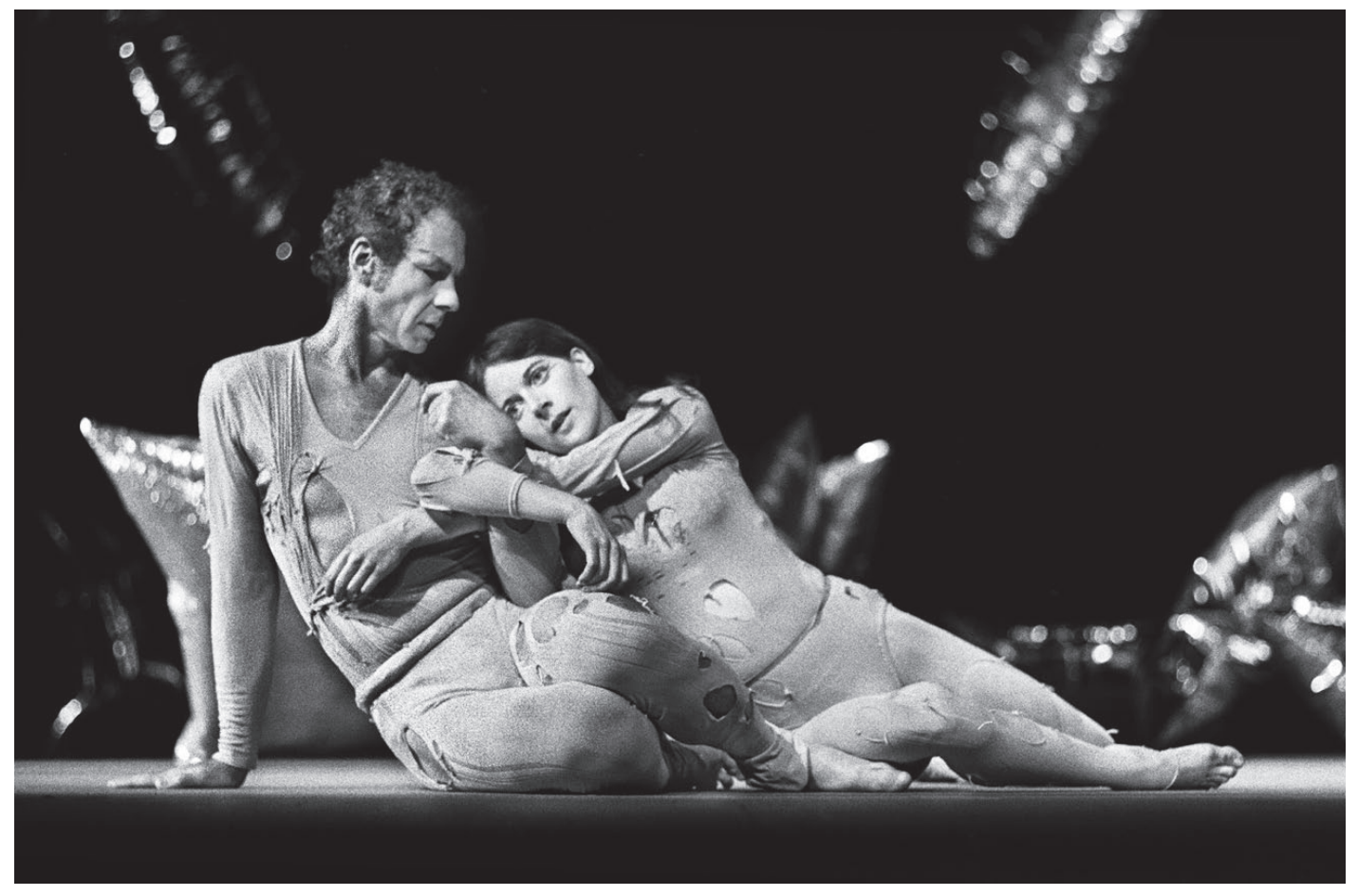

Fig. 3. Merce Cunningham, Selva, 1968 
Me refiero en concreto, al hecho de que para esta coreografía, Andy Warhol diseñó unos globos plateados, que son dispuestos al azar a lo largo del escenario, durante el tiempo en que se lleva a cabo toda la presentación. Para esta puesta en escena es fundamental el manejo de las luces y el reflejo de éstas en la superficie de los globos, dando lugar una serie de efectos visuales, que generan una atmósfera muy particular, como cuando la luz se trasluce a través de la densa vegetación en una selva. El juego de las luces es escena es un rasgo que está muy presente en las diversas propuestas de Cunningham, pues se combina estrechamente con la escenografía, con el vestuario y con el movimiento mismo de los bailarines. (Copeland, 2002, p. 18).

Como lo he mencionado previamente, uno de los rasgos más interesantes de Selva consiste en la interacción de los bailarines con los globos, pues al realizar sus desplazamientos, se encuentran con ellos y los mueven constantemente a través del escenario, por lo que este elemento no sólo tiene una connotación visual, sino también una carga espacial y plástica, que es central en esta coreografía. Aquí podemos hallar una diferencia notable entre esta propuesta y Camino al estanque, pues en el caso de esta última, la carga pictórica y escultórica de la escenografía aparece simplemente como un telón de fondo, que no permite una interacción directa con los bailarines, tal como lo logran los globos de Warhol.

En el marco de este componente coreográfico y visual que se asocia a la concepción estética del Pop Art es relevante mencionar que se trata de un objeto que puede resultar muy cotidiano y en un contexto que parecería muy alejado del terreno artístico, pero que al reinterpretarse origina una nueva carga simbólica, debido al modo en que se integra en la coreografía de Cunningham. De hecho esta apropiación de los globos, desde una perspectiva estética, a partir de los efectos visuales a los que dan lugar, podemos encontrarla también en la obra de artistas posteriores, como el caso de Jeff Koons, quien inspirado en la cultura popular, trabajó en una serie de esculturas metálicas de gran formato, entre el 2004 y el 2011 (Fig. 4), en las que evoca la textura, los colores, los efectos visuales y las figuras de animales, que suelen crearse mediante globos en las fiestas para niños.

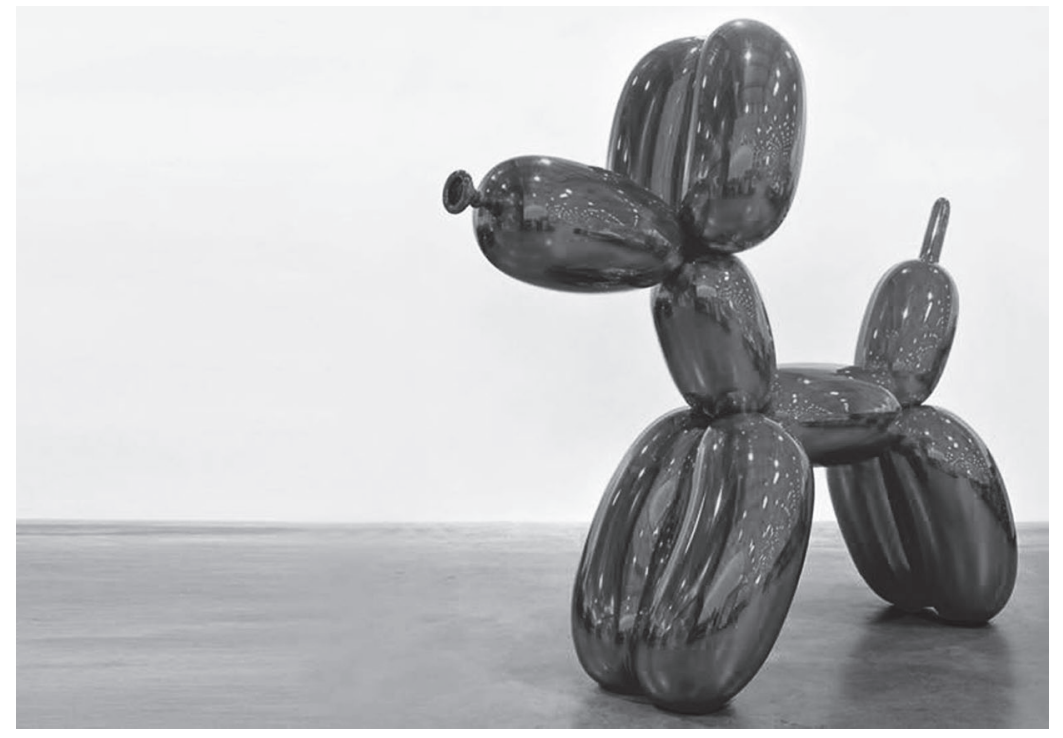

Fig. 4. Jeff Koons, Globos con figuras de animales, 2004-2011 Metal pulido con cubierta de color 
Finalmente deseo concluir hablando de Tiempo caminante, propuesta llevada a cabo en 1968 (Fig. 5) y en la que Jasper Johns colaboró con Cunningham, al inicio de su carrera. Lo peculiar de la escenografía diseñada por Johns para el coreógrafo estadounidense, consiste en que se trata de una especie de tributo a Marcel Duchamp, específicamente a su famosa obra conocida como El Gran Vidrio, realizada entre 1915 y 1923 (Fig. 6). Jasper Johns fragmenta minuciosamente todos los componentes de dicha obra de Duchamp, para crear unas esculturas con imágenes traslúcidas y situarlas en el escenario, lo que permite que los bailarines se desplacen alrededor de ellas, realizando movimientos mecánicos, que aluden a las máquinas eróticas y oníricas, que pueden apreciarse en El GranVidrio.

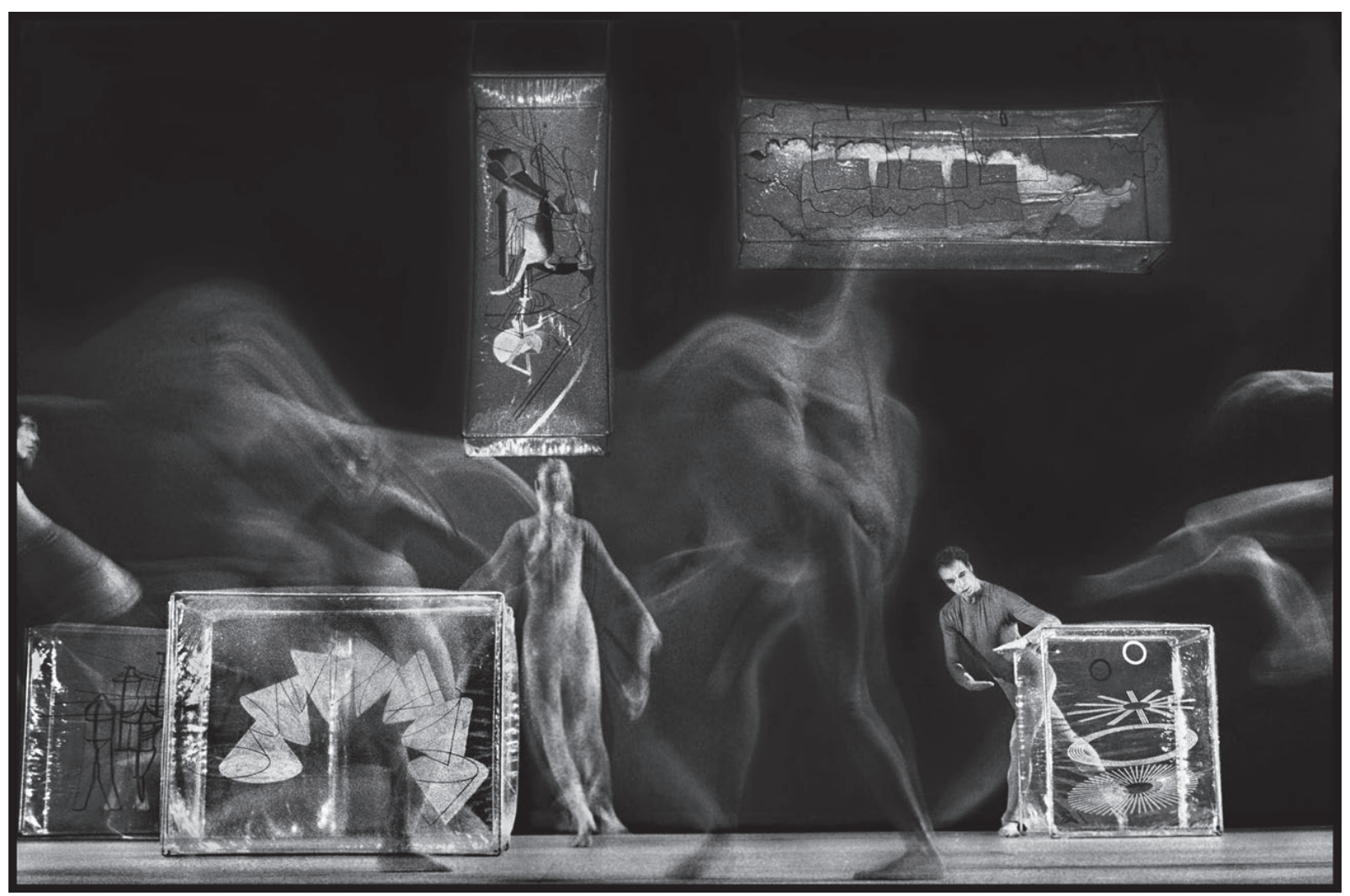

Fig. 5. Merce Cunningham, Tiempo Caminante, 1968 


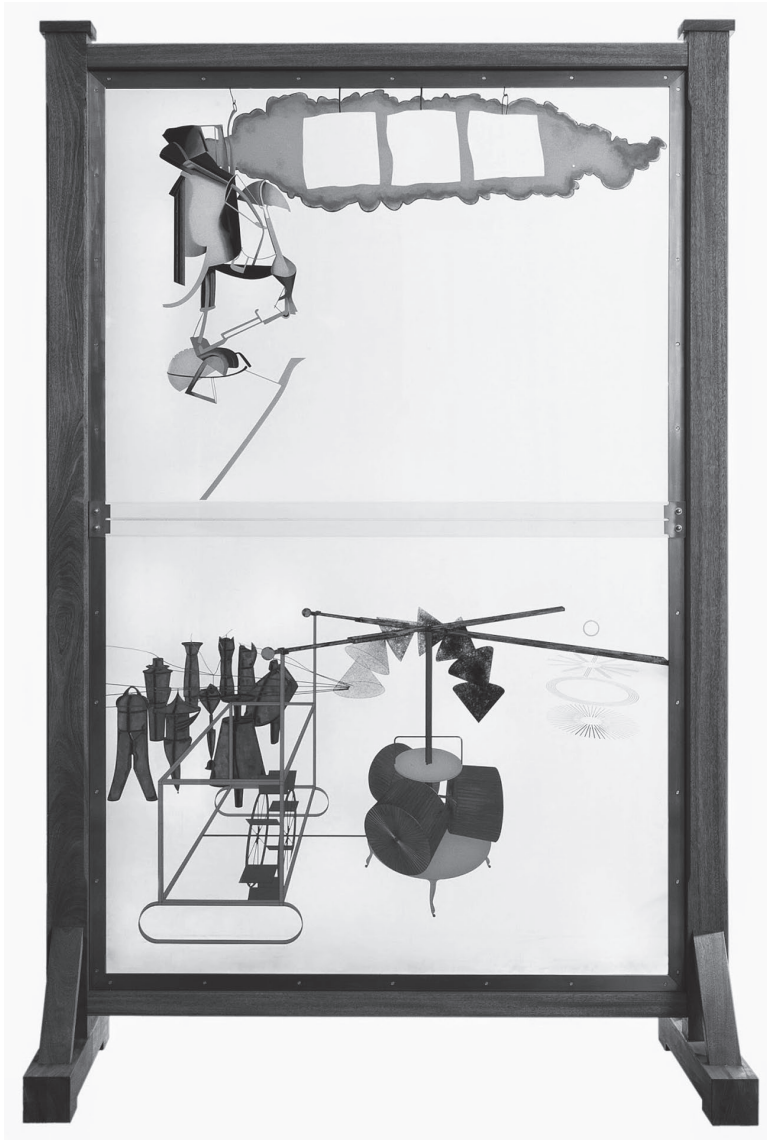

Fig. 6. Marcel Duchamp, El GranVidrio, 1915-1923 Óleo, barniz, polvo, lámina y alambre de plomo sobre dos placas de vidrio
Esto nos permite establecer una conexión con el interés que tuvo Duchamp, al inicio de su carrera, en la experimentación con la representación del movimiento, teniendo como eje la idea de simultaneidad espacial y temporal, así como la influencia que tuvo la cronofotografía en su trabajo pictórico. Estas inquietudes estéticas se reflejaron en un gran número de obras pictóricas, asociadas al cubismo y al futurismo, como es el caso de Desnudo bajando la escalera No. 12 de 1912 (Fig. 7), pero que en esa época no fue del todo aceptada, debido a que este artista francés no seguía sus principios con toda fidelidad. Al margen de la poca aceptación que tuvo su obra en el contexto europeo y de su habilidad técnica como pintor, pienso que es relevante la exploración que Duchamp realizó sobre el movimiento y su conexión con la ilusión óptica, lo que constituye una fuente de inspiración para que Johns desarrollara su propuesta escenográfica para Tiempo Caminante.

Fig. 7. Marcel Duchamp, Desnudo bajando la escalera No. 2, 1912. Óleo sobre tela

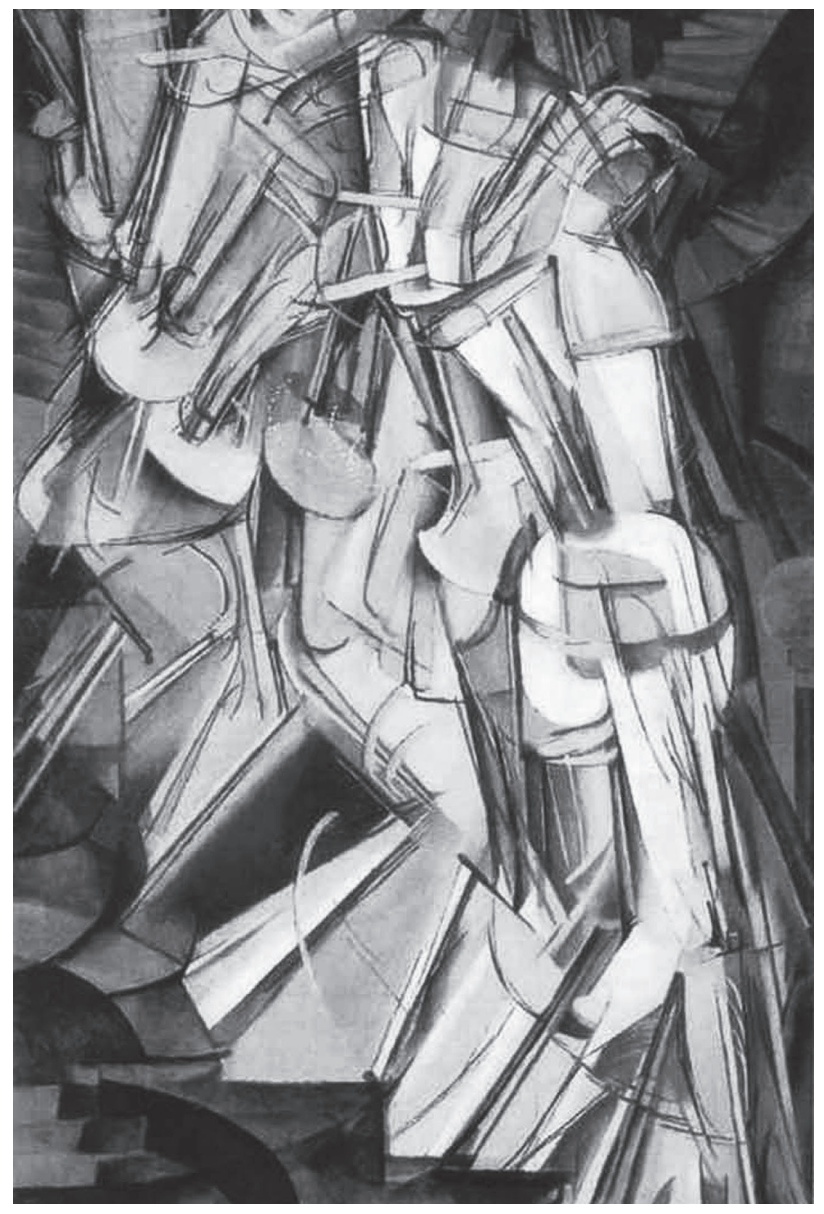


Algo que considero muy bien logrado de la escenografía realizada por Johns es que se da cuenta de los efectos visuales que produce la transparencia del vidrio, de la obra original de Duchamp, lo que implica que tanto el espacio donde se ubica, como el paso del público, altera la pieza y genera una nueva experiencia sobre ella, pues cambia constantemente. En este sentido, Jasper Johns se apropia del trabajo de Duchamp de dos modos, en primer lugar toma en cuenta la transparencia del material, al crear unos módulos que pueden moverse en el escenario y sobre todo que permiten apreciar el tránsito de los bailarines, en torno a dichas piezas. Por otro lado, Johns deconstruye la totalidad de El GranVidrio, en sus componentes más simples y los reconstruye en escena, desde una perspectiva totalmente distinta, con lo que logra traducir la estética del collage pictórico al contexto dancístico, pues las propiedades plásticas y visuales de la escenografía entran en diálogo con el despliegue corporal y los movimientos de los bailarines.

A manera de conclusión, me gustaría resaltar algunos aspectos que encuentro en las tres coreografías revisadas, a partir de las categorías que he planteado para examinar los proyectos dancísticos de Merce Cunnnigham. En primer lugar, las diversas coreografías que he analizado, no sólo nos muestran la intensa colaboración e influencia que existió entre este gran bailarín y artistas de otras disciplinas, sino que nos revelan cómo la concepción pictórica de Roy Lichtenstein, Andy Warhol y Marcel Duchamp, se traduce en efectos plásticos y visuales muy particulares, que no son equiparables entre sí y que potencializan diversos aspectos del espacio escénico, del cuerpo de los bailarines y de sus movimientos en escena.

También considero que las propuestas plásticas y visuales de los artistas con los que trabajó Cunningham, no se circunscriben meramente al adorno del escenario, con elementos que resulten visual y plásticamente atractivos, sino que se trata de una experimentación constante con los procesos creativos, dando lugar a hibridaciones, que difuminan notablemente los límites entre disciplinas artísticas. De aquí que cada propuesta escénica y coreográfica llevada a cabo entre Cunningham y los artistas seleccionados, produzca una gran variedad de experiencias e interpretaciones, debido a que genera una interacción muy particular con los bailarines, lo que también da lugar a una aproximación distinta por parte del público.

Por último, considero que a pesar de la yuxtaposición de elementos, la heterogeneidad de estímulos sensibles y el rechazo a una perspectiva integral en la propuesta dancística de Merce Cunningham, sí es posible encontrar un cierto sentido de unidad, entre esta gran variedad de componentes artísticos, que en el fondo generan un diálogo entre las cualidades de la escenografía, el diseño del vestuario, el manejo de las luces en escena y las propiedades plásticas y visuales, a las que dan lugar los bailarines. Esto hace posible apreciar e interpretar la danza, a través de una muy particular concepción del collage, que ya no puede entenderse de manera estática, como ocurría en las obras plásticas y visuales que le dieron origen, sino que se transfigura y cobra vida, gracias a los cuerpos en movimiento. 


\section{Referencias}

Copeland, R. (2002). Cunningham and the Aesthetic of Collage. The Drama Review, 46 (1), 11-28.

. (1999). Cunningham, Collage, and the Computer.A Journal of Performance and Art, 21(3), 42-54.

Cunningham, M. (1999). “Music and Dance”. En R. Kostelanetz (Ed.), Writings about John Cage (pp. 338340). Michigan: Universidad de Michigan.

Johnston, J. (1999). "Cage and Modern Dance”. En Writings about John Cage (pp. 334-337), Michigan: Universidad de Michigan.

Kostelanetz, R. (1999). “The Development of His Visual Art”. En R. Kostelanetz (Ed.), Writings about John Cage (pp. 323-326), Michigan: Universidad de Michigan.

Vaughan, D. (1999). “Merce Cunningham: Origins and Influences”. En R. Kostelanetz (Ed.), Writings about John Cage (pp. 327-333), Michigan: Universidad de Michigan.

\section{Imágenes}

Fig. 1. Walker Art Center. (2011). Merce Cunningham Dance Company:The Legacy Tour. Minneapolis, Estados Unidos. Recuperada de http://blogs.walkerart.org/performingarts/2011/11/05/penelopefree-reviews-merce-cunningham-dance-company-the-legacy-tour/

Fig. 2. The Art Institute of Chicago. (2013). Roy Lichtenstein. A Retrospective. Chicago, Estados Unidos. Recuperada de http:/ / www.artic.edu/aic/collections/exhibitions/Lichtenstein/ artwork/213407

Fig.3. Rambert Dance Company. (2010). The Art of Touch. Rainforest. Londres, Inglaterra. Recuperada de http: / /www.ballet.co.uk/magazines/yr_10/jun10/bm_rev_rambert_0510.htm

Fig.4. Art Observed. (2013). Jeff Koons at Gagosian Gallery. Nueva York, Estados Unidos. Recuperada de http: / / artobserved.com/2013/05/new-york-jeff-koons-at-gagosian-gallery-through-june29th-2013/

Fig.5. The Brooklyn Rail. (2011). Nine Goodbyes. Nueva York, Estados Unidos. Recuperada de http:// www.brooklynrail.org/2011/12/dance/nine-goodbyes

Fig.6. The Tate Gallery. (2015). The Large Glass. Londres, Inglaterra. Recuperada dehttp:/ /www.tate. org.uk/art/artworks / duchamp-the-bride-stripped-bare-by-her-bachelors-even-the-largeglass-t02011

Fig.7. Philadelphia Museum of Art.(2015). Nude Descending a Staircase, No. 2. Filadelfia, Estados Unidos. Recuperada de http://www.philamuseum.org/collections/permanent/51449.html 